\title{
青海湖裸鲤(湟鱼)鱼骨产出层位及其耳石微化学 对明朝青海湖水位的指示
}

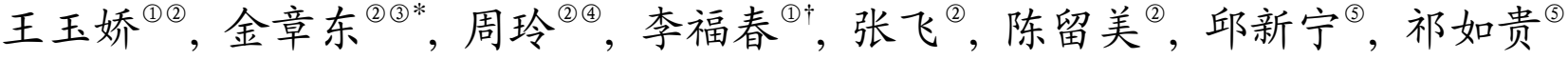 \\ (1) 南京农业大学资源与环境科学学院, 南京 210095 ; \\ (2) 中国科学院地球环境研究所黄土与第四纪地质国家重点实验室, 西安 710075; \\ (3) 西安交通大学全球环境变化研究院, 西安 710049; \\ (4) 中国科学院大学, 北京 100049 ; \\ (5) 青海省水文水资源勘测局，西宁 810001 \\ * 联系人, E-mail: zhdjin@ieecas.cn \\ $\dagger$ 联系人, E-mail: fchli@njau.edu.cn
}

收稿日期: 2013-02-23; 接受日期: 2013-09-04; 网络版发表日期: 2014-07-11

国家重点基础研究发展计划项目(编号: 2010CB833400)和国家自然科学基金项目(批准号: 41225015, 41172308)资助

\begin{abstract}
摘要鱼耳石是硬骨鱼类内耳中的生物碳酸盐矿物, 其组成可以记录鱼体生活水体的物理 和化学状况. 以青海湖鸟岛附近发现的青海湖裸鲤鱼骨及耳石为研究对象, 通过古代和现代耳 石微化学组成的对比分析, 结合裸鲤鱼骨及耳石 $\mathrm{AMS}-{ }^{14} \mathrm{C}$ 定年、产出层位和周边地形, 认为这 些裸鲤是小冰期时青海湖高湖面退却形成的残余湖内生长的. 通过保存的青海湖裸鲤鱼骨和 耳石的 AMS $-{ }^{14} \mathrm{C}$ 定年, 确定这些裸鲤生活的时代距今 300 680 年左右, 即我国历史上的明朝时 期. X 射线衍射图谱表明, 青海湖裸鲤古代微耳石的矿物是纯文石, 这与现代微耳石一致, 说明 埋藏后微耳石的矿物类型没有发生变化, 可用于对比分析. 微化学分析结果表明, 古代微耳石 的 $\mathrm{Mg} / \mathrm{Ca}$ 比值 $\left((70.12 \pm 18.50) \times 10^{-5}\right)$ 和 $\delta^{18} \mathrm{O}$ 值 $(1.76 \%$ o $1.03 \%$ ) 均明显高于现代微耳石 $(\mathrm{Mg} / \mathrm{Ca}$ 平 均值为 $(3.11 \pm 0.41) \times 10^{-5}, \delta^{18} \mathrm{O}$ 平均值为 $-4.82 \% 0 \pm 0.96 \%$ ). 这反映了明朝时青海湖裸鲤生活的水 体具有比现代青海湖高得多的 $\mathrm{Mg} / \mathrm{Ca}$ 和 $\delta^{18} \mathrm{O}$ 值, 这是与大湖隔离后强烈蒸发浓缩的结果, 类似 于现代的不海等. 根据裸鲤鱼骨产出的层位和海拔高度, 推断明朝时期青海湖的湖面海拔至少 达到 $3202 \mathrm{~m}$, 经计算当时的湖面面积至少为 $4480 \mathrm{~km}^{2}$, 比现在大 $5 \%$ 左右.
\end{abstract}

关键词

青海湖裸鲤

鱼骨

微耳石

氧同位素

$\mathrm{Mg} / \mathrm{Ca}$

湖泊水位
青海湖地处青藏高原的东北部 $\left(99^{\circ} 36^{\prime} \sim 100^{\circ} 47^{\prime} \mathrm{E}\right.$, $\left.36^{\circ} 32^{\prime} \sim 37^{\circ} 15^{\prime} \mathrm{N}\right)$, 是我国最大的内陆微咸水湖. 它位 于我国半干旱区, 其气候受东亚季风、印度季风和西 风的共同影响, 对气候变化的响应十分敏感. 恢复不
同时期的湖泊水位, 可以反演区域降水或有效湿度 状况, 对于进一步探讨环境变化具有重要意义. 自 1958 年有水位记录以来, 青海湖水位的总体趋势在 下降，且下降趋势明显． Li 等(2007)计算出从 1959

中文引用格式: 王玉娇, 金章东, 周玲, 等. 2014. 青海湖裸鲤(湟鱼)鱼骨产出层位及其耳石微化学对明朝青海湖水位的指示. 中国科学: 地球科学, 44: 1833-1843

英文引用格式: Wang Y J, Jin Z D, Zhou L, et al. 2014, Stratigraphy and otolith microchemistry of the naked carp Gymnocypris przewalskii (Kessler) and their indication for water level of Lake Qinghai during the Ming Dynasty of China. Science China: Earth Sciences, doi: 10.1007/s11430-014-4836-1 
2000 年, 青海湖水位以平均 $8.0 \mathrm{~cm} \mathrm{a}^{-1}$ 的速度下降了 $3.35 \mathrm{~m}$. 然而, 2005 年以来, 青海湖水位开始回升, 连续 7 年呈增长趋势. 因此, 青海湖的水位变化、趋 势及其原因一直受到关注 ( $\mathrm{Li}$ 等, 2007; 伊万娟等, 2010). 在较短时间尺度上, 关于青海湖高湖面的出 现年代存在着不同的看法(王苏民和李建仁，1991； 冯松等, 2000). 在长时间尺度上, 对于青海湖高湖面 的出现阶段以及高度, 更是存在诸多的争议和不确 定性(王苏民和施雅风, 1992; Zhang 等, 2004; Madsen 等, 2008; Rhode 等, 2010). 然而, 通过青海湖周围的 湖岸沙堤、湖积阶地开展的高湖面年代和形成机制研 究, 由于阶地鉴别、测年材料和定年方法等方面的原 因，存在很大的分歧. 例如，在青海湖湖岸堤砂砾沉 积物中很难找到适合 ${ }^{14} \mathrm{C}$ 测年的有机物质, 这使得 ${ }^{14} \mathrm{C}$ 测年方法的应用受到了限制(刘向军和赖忠平, 2010), 以及青海湖沉积物吸收了周围冰川融化带来 的老碳, 可能使得 ${ }^{14} \mathrm{C}$ 年龄偏老( $\mathrm{An}$ 等, 2012), 而不同 研究者利用光释光方法获得的年龄差异更大(Madsen 等, 2008; Rhode 等, 2010; 刘向军和赖忠平, 2010)等.

青海湖裸鲤, 俗名湟鱼, 是在青海湖的形成发展 过程中经过长期演化的鱼种, 具有耐盐碱、耐寒和集 群等特点, 处于青海湖整个生态系统的核心地位. 鱼 耳石是硬骨鱼类内耳中最先钙化的生物成因碳酸盐 矿物, 从鱼体的胚胎期就开始生长, 并伴随着鱼类的 整个生命过程. 重要的是, 由于耳石是非细胞并具有 代谢惰性的结构, 沉淀后其组分不会发生变化. 因此, 耳石可以完整地记录鱼体生活的周围水体的物理和 化学状况. 如 Elsdon 等(2004)通过实验室控制实验发 现布氏棘鲖耳石的 $\mathrm{Sr}$ 和 Ba 浓度主要与生活水体的温 度以及 $\mathrm{Sr}$ 和 $\mathrm{Ba}$ 浓度有关; Gillanders 等(2012)测试了 小口坚银汉鱼耳石中的六种元素和 $\delta^{18} \mathrm{O}$ 在大盐度范 围的水环境中与水化学组成的关系, 发现耳石的 $\mathrm{Mg} / \mathrm{Ca}$ 比值与水体的 $\mathrm{Mg} / \mathrm{Ca}$ 比值呈线性关系. 我们 已开展的有关青海湖裸鲤耳石的研究表明, 微耳石 由纯文石构成, 其 $\mathrm{Sr} / \mathrm{Ca}$ 比值能示踪青海湖裸鲤所生 活的水体化学(周玲等, 2012). 由于没有储库效应 (reservoir effect), 保存在沉积物中的鱼骨及耳石更是 测定放射性碳的良好材料. 例如, Kerr 等(2004)通过 测定黄眼石斑鱼的耳石环带建立了 1940 1990 年阿 拉斯加东南部沿海水域 ${ }^{14} \mathrm{C}$ 含量变化曲线. 同时, 利 用保存完整的耳石化石的 $\delta^{18} \mathrm{O}$ 值可以推测海水表面 温度变化(Andrus 等, 2002). 因此, 耳石化石既是确
定沉积年代的理想材料之一, 又是研究古气候环境 的良好载体.

本文以青海湖鸟岛附近发现的青海湖裸鲤鱼骨 和耳石为测年对象, 获得了可靠的年代, 进而对比现 代和古代微耳石的微化学组成 $\left(\mathrm{Mg} / \mathrm{Ca}\right.$ 和 $\delta^{18} \mathrm{O}$ 值), 结 合采样点的地形、地貌和沉积相, 推断了明朝时期青 海湖的一次高湖面, 这将为认识历史时期青海湖的 环境状况和湖泊演化提供新的认识.

\section{1 材料和测试方法}

\section{1 青海湖自然地理概况}

青海湖目前的湖面海拔为 $3194 \mathrm{~m}$, 湖区面积 $4260 \mathrm{~km}^{2}$, 水容量 716 亿 $\mathrm{m}^{3}$, 流域面积 $29660 \mathrm{~km}^{2}$. 作 为微咸水湖, 青海湖现代湖水盐度为 $15.5 \mathrm{~g} \mathrm{~L}^{-1}, \mathrm{pH}$ 为 9.06. 汇入青海湖的河流包括西部的布哈河, 北部 的沙柳河、泉吉河和哈尔盖河, 南部的黑马河, 东部 的倒淌河流入已与大湖分离的耳海中. 其中, 布哈河 是青海湖流域最大的河流, 贡献了入湖径流量的 $50 \%$ 以上, 也是青海湖裸鲤的主要洄游产卵场所.

青海湖流域为高原大陆性气候, 光照充足、日照 剧烈、冬寒夏凉, 春季多大风和沙暴, 雨量偏少. 该 地区年平均降雨量(1951 2005)为 $336.6 \mathrm{~mm} \mathrm{a}^{-1}$, 蒸发 量约为降雨量的 3 4 倍( $\mathrm{Li}$ 等, 2007). 青海湖地区年 平均气温(1951 2005) 是 $1.2^{\circ} \mathrm{C}$, 湖水夏季水温分层 (表层水温约 $12 \sim 15^{\circ} \mathrm{C}$, 底层水温小于 $6^{\circ} \mathrm{C}$ ), 湖面从 10 月份到次年 4 月份结冰(Yan 等, 2002). 青海湖裸鲤就 生活在这种高盐度和碱度、冬夏季节温度存在显著 反差的湖水中, 每年的 5 9 月洄游到淡水河流中进行 繁殖.

\section{2 样品采集与预处理}

实验样品是从青海湖采集的现代野生青海湖裸 鲤内耳中取出的微耳石和 2011 年 5 月从鸟岛附近湖 边阶地沉积层中采集的鱼骨残片及古代耳石. 这些 保存在 $25 \mathrm{~cm}$ 厚沉积物中的鱼骨, 呈叠层状, 包含鱼 的各个部分; 耳石外形完整, 其形状和矿物组成与现 生青海湖裸鲤耳石一致，因此这些鱼骨和耳石是属 于原地埋藏的青海湖裸鲤. 根据周玲等(2012)对现生 裸鲤三对耳石形状和矿物组成的分析, 我们从采集 的鱼骨残骸中挑出了 9 个微耳石样品用于分析. 同时 还挑出了一些鱼骨残片, 经过清洗并烘干后待用. 
将挑出的微耳石放入离心管中, 用 $\mathrm{H}_{2} \mathrm{O}_{2}$ 溶液和 蒸馏水依次交换清洗 3 次, 以清除耳石上的杂质, 然 后放在烘箱中烘干备用. 将烘干后的一部分微耳石 放入包埋板封埋于环氧树脂, 放入烘箱, 温度 $40^{\circ} \mathrm{C}$ 下烘干 50 60 min, 树脂硬化后取出; 用慢速切割机 切割成适当大小后, 利用平置转盘式研磨机, 先以 1600 号的砂纸沿着横切面作初步研磨, 然后换用 1200 号的砂纸研磨, 这个过程中应不断在显微镜下 观察, 以保证恰好磨至耳石的核心出现. 再以线布加 氧化铝粉 $\left(\mathrm{Al}_{2} \mathrm{O}_{3}\right)$ 抛光其表面, 在显微镜下分别用反 射光和透射光进行观察并照相, 之后便可作氧同位 素和 $\mathrm{Mg} / \mathrm{Ca}$ 比值的测试分析.

\section{3 测试方法}

\subsection{1 青海湖裸鲤鱼骨及耳石 $\mathrm{AMS}-{ }^{14} \mathrm{C}$ 测年}

挑选残骸中的鱼骨和 2 颗古代耳石, 以及同时采 集的 1 颗现代耳石, 进行 AMS- ${ }^{14} \mathrm{C}$ 定年. 鱼骨样品前 处理方法为酸-碱-酸法(Yuan 等, 2000), 前处理和测 年过程在西安加速器质谱中心完成. 具体前处理过 程分 5 步完成. (1) 将样品在超声波振荡器中振荡约 $30 \mathrm{~min}$, 彻底清洗骨质样品中吸附的泥土等物质, $60^{\circ} \mathrm{C}$ 烘干、粉碎, 保证样品均匀; (2) 提取骨胶原: 在 样品中加入 $0.5 \mathrm{~N} \mathrm{HCl}$, 静置过夜, 然后过滤, 固体部 分(骨胶原)洗涤至中性; (3) 碱洗: 加入 $0.5 \mathrm{~N} \mathrm{NaOH}$, 放置 $30 \mathrm{~min}$, 以除去样品中可能存在的腐殖酸, 然后 用去离子水洗涤至中性; (4) 骨胶原水解: 样品中加 入去离子水, 然后加入 $1 \mathrm{~mol} / \mathrm{L} \mathrm{HCl}$, 调节溶液 $\mathrm{pH}=3$ 左右, 放置在 $90^{\circ} \mathrm{C}$ 水浴中静置, 直到骨胶原全部水解 为明胶, 冷冻干燥, 装瓶备用. 最后, 将上述制备好 的样品装入 $9 \mathrm{~mm}$ 石英管中, 加入过量氧化铜, 接入 真空系统中, 当真空到达 $5 \times 10^{-5}$ torr 时, 燃烧样品, 反应生成 $\mathrm{CO}_{2}$. 利用 $\mathrm{Zn} / \mathrm{Fe}$ 法将生成的 $\mathrm{CO}_{2}$ 还原为石 墨, 最后在 $3 \mathrm{MV}$ 加速器上进行测试. 耳石样品的前 处理方法为酸溶法: 将样品在超声波中振荡约 $30 \mathrm{~min}$, 彻底清洗耳石表面的污染物, $60^{\circ} \mathrm{C}$ 烘干; 用稀盐酸清 洗耳石表面, 然后用蒸馏水洗涤至中性, 烘干备用; 在 研钵中粉碎样品, 将样品置于反应瓶中, 加入稀盐酸 在真空下反应完全, 收集 $\mathrm{CO}_{2}$, 将 $\mathrm{CO}_{2}$ 还原成石墨靶 进行加速器测试. 该前处理和 AMS- ${ }^{14} \mathrm{C}$ 测年在 BETA 实验室完成. 最后, 利用 Calib 6.01 校正程序将测试 获得的 ${ }^{14} \mathrm{C}$ 年龄校正为日历年龄 (Reimer 等, 2009).

\subsection{2 青海湖裸鲤古代微耳石的 XRD 测定}

为确定微耳石在埋藏后其矿物类型是否发生变 化, 我们对古代微耳石样品进行了矿物组成分析. 在 玛瑙研钵中研磨微耳石至 200 目, 以乙醇为溶剂将样 品涂在 $\mathrm{Si}$ 无反射样品架上, 自然晾干. 利用 Rigaku $\mathrm{D} / \mathrm{Max} 2500$ 型转靶 $\mathrm{X}$ 射线衍射仪测定矿物成分. 测 定条件为: $\mathrm{Cu}$ 靶, 石墨单色器, 工作电压 $40 \mathrm{kV}$, 工 作电流 $200 \mathrm{~mA}$, 步长 $0.02^{\circ}$, 扫描速度 $4 \% \mathrm{~min}$, 扫描 范围为 $5^{\circ} \sim 70^{\circ}(2 \theta)$. 本测试在国土资源部南京地质矿 产检测中心完成.

\subsection{3 青海湖裸鲤现代和古代微耳石的氧同位素 $\left(\delta^{18} \mathrm{O}\right)$ 测试}

将微耳石切片固定在载玻片上, 然后采用 Micromill 系统取样. 该系统由 $x-y$ 方向的载物台以及 在垂直 $(z)$ 方向上可移动的不锈钢钻头组成, 该钻头 可以以 $1 \mu \mathrm{m}$ 的精度沿着所有轴移动. 取样时, 沿着 长轴从耳石的边缘向核心方向以大约 $100 \mu \mathrm{m}$ 的间隔 依次取样, 取样深度 $0.2 \sim 0.3 \mathrm{~mm}$, 将采集好的粉末收 集到 $10 \mathrm{~mL}$ 玻璃瓶中, 每个样品 $20 \mu \mathrm{g}$ 左右.

采集好的耳石粉末样品在中国科学院地球环境 研究所稳定同位素实验室的 Finnigan MAT 252 上完 成测试, 该仪器配有 Kiel II 碳酸盐微量自动进样装 置. 测得的 $\delta^{18} \mathrm{O}$ 值采用 VPDB 标准, 所用标准样品 为 TTB 1 , 每 20 个样品插一个标样进行监控, 氧同位 素分析精度为 $\pm 0.2 \%$ 。

\subsection{4 青海湖裸鲤现代和古代微耳石中 $\mathrm{Mg}$ 和 $\mathrm{Ca}$ 含量测定}

在西北大学的大陆动力学国家重点实验室利用 激光剥蚀电感耦合等离子质谱仪(LA-ICP-MS)进行 原位微区分析，检测微耳石样品从核心至边缘、不同 生长环带中的 $\mathrm{Mg}, \mathrm{Ca}$ 含量. 检测的斑束直径 $40 \mu \mathrm{m}$, 单脉冲能量 $200 \mathrm{~mJ}$, 激光频率 $10 \mathrm{~Hz}$, 功率 $1320 \mathrm{~W}$, 信号测量时间 $40 \mathrm{~S}$, 背景测量时间 $30 \mathrm{~S}, \mathrm{He}$ 载气流速 $0.67 \mathrm{~L} / \mathrm{min}$. 微耳石中 $\mathrm{Mg}$ 计数率 (count per second) 的 相对标准偏差 $(\mathrm{RSD})$ 平均值为 $3.29 \%, \mathrm{Ca}$ 的 $\mathrm{RSD}$ 为 0 .

\section{2 结果}

\section{1 青海湖裸鲤鱼骨残骸产出层位及埋藏沉积相} 青海湖裸鲤鱼骨残骸采样点位于鸟岛附近(图 1), 


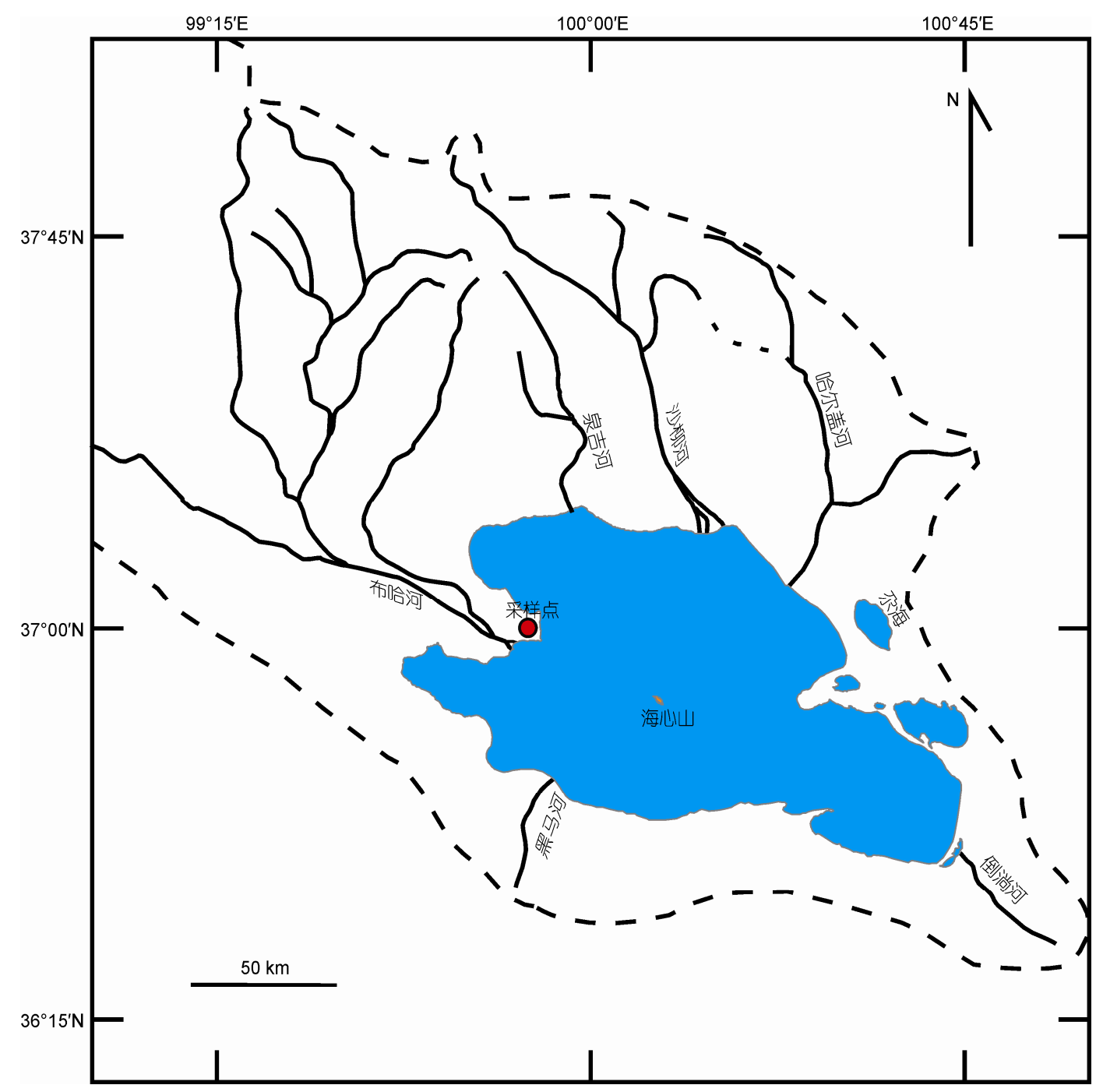

图 1 青海湖和周围主要河流分布以及裸鲤鱼骨采样点的位置

布哈河、沙柳河、泉吉河、黑马河和哈尔盖河为青海湖裸鲤洄游的 5 条主要河流, 虚线为青海湖流域界线, 红点为采样点位置

地理坐标为 $\left(99^{\circ} 52^{\prime} 21.8^{\prime \prime} \mathrm{E}, 36^{\circ} 58^{\prime} 43.5^{\prime \prime} \mathrm{N}\right)$. 根据沉积 物剖面不同沉积相的特征, 我们将其从上到下分为 4 层(图 2): 第 1 层为粉砂质类黄土, 第 2 层为含砾石的 细砂，底部赋存少量鱼骨等残骸，第 3 层为含粗砂的 细砂，第 4 层为含砾石的中细粒砂，赋存大量鱼骨等 残骸, 特别是底部 $9 \mathrm{~cm}$, 该层为本文所用样品的主要 采集层位，其绝对高程为 $3202 \mathrm{~m}$. 根据砾石呈扁平 状并大致水平排布等特征来判断，保存裸鲤鱼骨残 骸的沉积物属于湖滨相.

\section{2 青海湖裸鲤耳石及鱼骨年龄}

用于 ${ }^{14} \mathrm{C}$ 测年的有机质往往存在不同程度的“储
库效应”(Watanabe 等, 2009), 并可能在沉积后受到植 物等的影响, 导致测得的年龄不准确, 而鱼骨、叶片 等生物残体却可获得可靠的 ${ }^{14} \mathrm{C}$ 组成(Kerr 等, 2004), 因此我们利用鱼骨残片、现生和古代的鱼耳石进行 AMS $-{ }^{14} \mathrm{C}$ 对比分析, 进而确定裸鲤鱼骨等残骸的埋 藏年代. 耳石及鱼骨 $\mathrm{AMS}-{ }^{14} \mathrm{C}$ 测年结果(表1)表明, 现代鱼骨和耳石的 ${ }^{14} \mathrm{C}$ 年龄均为 0 , 说明鱼骨和耳石 均不存在老碳的“储库效应”. 将 BETA 和 Xi' an-AMS 两个实验室测得的鱼骨残片和古代耳石的 $\mathrm{AMS}-{ }^{14} \mathrm{C}$ 年龄校正后, 得到裸鲤鱼骨等残骸的年龄距今大约 $300 \sim 680$ 年, 涵盖了我国历史上的整个明代(公元 1368 1644 年). 


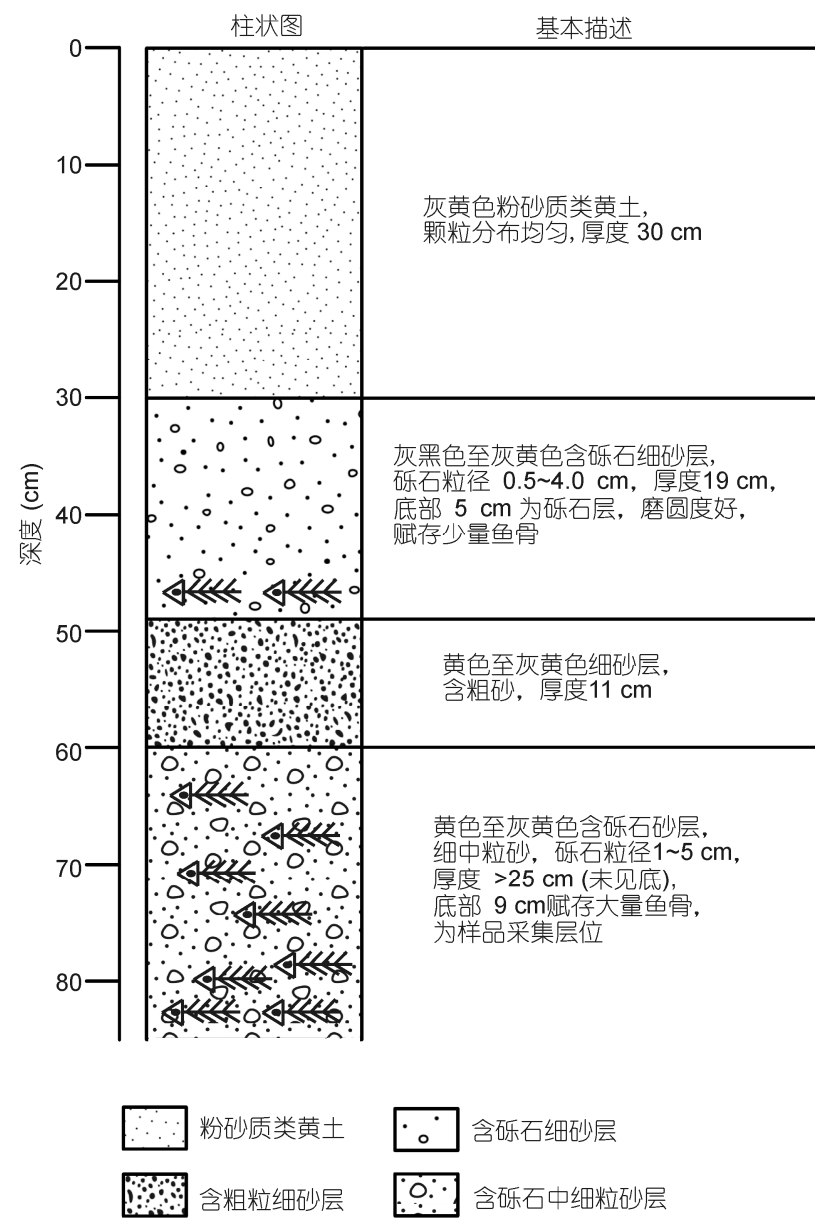

图 2 青海湖裸鲤鱼骨产出的沉积物剖面柱状图和采样层位

\section{3 青海湖裸鲤古代微耳石的矿物组成}

考虑到现生裸鲤的微耳石由纯文石组成, 而化 学成因的文石是一种亚稳定的矿物(Jamieson, 1953; Gago-Duport 等, 2008), 因此在进行化学分析之前, 最重要的是确定这些埋藏了几百年的微耳石的矿物 成分是否发生了相变. XRD 图谱(图3)表明, 青海湖 裸鲤古代微耳石的矿物类型是纯文石, 这与现代微
耳石的矿物成分(周玲等, 2012)是完全相同的(图 3). 青海湖裸鲤古代和现代微耳石的 XRD 图谱对比发现, 无论是在谱线位置还是相对强度上, 两者都完全一 致. 这说明, 经过几百年的埋藏, 微耳石的矿物类型 并没有发生变化. 同时, 这也暗示着, 与化学成因的 文石不同，生物成因的文石具有稳定性，这也进一步 说明采集的古代微耳石的物理和化学组成没有随着 时间发生变化, 从而更有利于通过耳石微化学组成 提取裸鲤生活时的水环境信息.

\section{4 青海湖裸鲤现代和古代微耳石氧同位素组成 及其差异}

青海湖裸鲤现代微耳石的 $\delta^{18} \mathrm{O}$ 值变化于-6.68\% $-2.68 \%$, 平均值为 $(-4.82 \pm 0.96) \%$, 而古代微耳石的 $\delta^{18} \mathrm{O}$ 值变化范围为 $-0.44 \%$ $2.92 \%$, 平均值为 $(1.76 \pm$ $1.03) \%$ o(图 4). 古代微耳石比现代微耳石的 $\delta^{18} \mathrm{O}$ 值平 均高了大约 6\%o, 经 $T$ 检验得出 $P=0.000(<0.01)$, 说明 青海湖裸鲤现代和古代微耳石的 $\delta^{18} \mathrm{O}$ 值差异极显著.

\section{5 青海湖裸鲤现代和古代微耳石 $\mathrm{Mg} / \mathrm{Ca}$ 比值及 其差异}

青海湖裸鲤古代微耳石的 $\mathrm{Mg} / \mathrm{Ca}$ 比值主要在 $24.91 \times 10^{-5} \sim 126.96 \times 10^{-5}$ 变化, 平均值为 $(70.12 \pm 18.50) \times$ $10^{-5}$, 而现代微耳石的 $\mathrm{Mg} / \mathrm{Ca}$ 比值的变化范围为 $2.29 \times 10^{-5} \sim 4.55 \times 10^{-5}$, 平均值为 $(3.11 \pm 0.41) \times 10^{-5}$ (图 5). 古代微耳石比现代微耳石的 $\mathrm{Mg} / \mathrm{Ca}$ 比值高了约 23 倍, 经 $T$ 检验得出 $P=0.000(<0.01)$, 说明青海湖裸鲤现代 和古代微耳石的 $\mathrm{Mg} / \mathrm{Ca}$ 比值差异也极为显著.

\section{3 讨论}

鱼耳石化学组成能很好地记录鱼体生活的水体 环境, 并能够完整保存在沉积物中, 因此耳石化石常

表 1 青海湖裸鲤古代和现代耳石及鱼骨 $\mathrm{AMS}-{ }^{14} \mathrm{C}$ 测年结果及校正年龄 ${ }^{\mathrm{a})}$

\begin{tabular}{|c|c|c|c|c|}
\hline 实验室编号 & 定年材料 & 测定的 ${ }^{14} \mathrm{C}$ 年龄 (a BP) & 校正年龄(cal. a BP) & 实验室 \\
\hline 311884 & 古代耳石 & $270 \pm 30$ & $287 \sim 424$ & BETA \\
\hline 311885 & 古代耳石 & $420 \pm 30$ & $657 \sim 681$ & BETA \\
\hline XA6480 & 古代鱼骨 & $333 \pm 25$ & $317 \sim 445$ & Xi'an-AMS \\
\hline 311886 & 现代耳石 & $112.3 \pm 0.3 \mathrm{pMC}$ & 0 & BETA \\
\hline AA78730 & 现代鱼骨 & 0 & - & NSF-AMS in Tucson \\
\hline
\end{tabular}

a) “pMC”为现代碳的百分比; AA78730 数据来自 An 等(2012) 


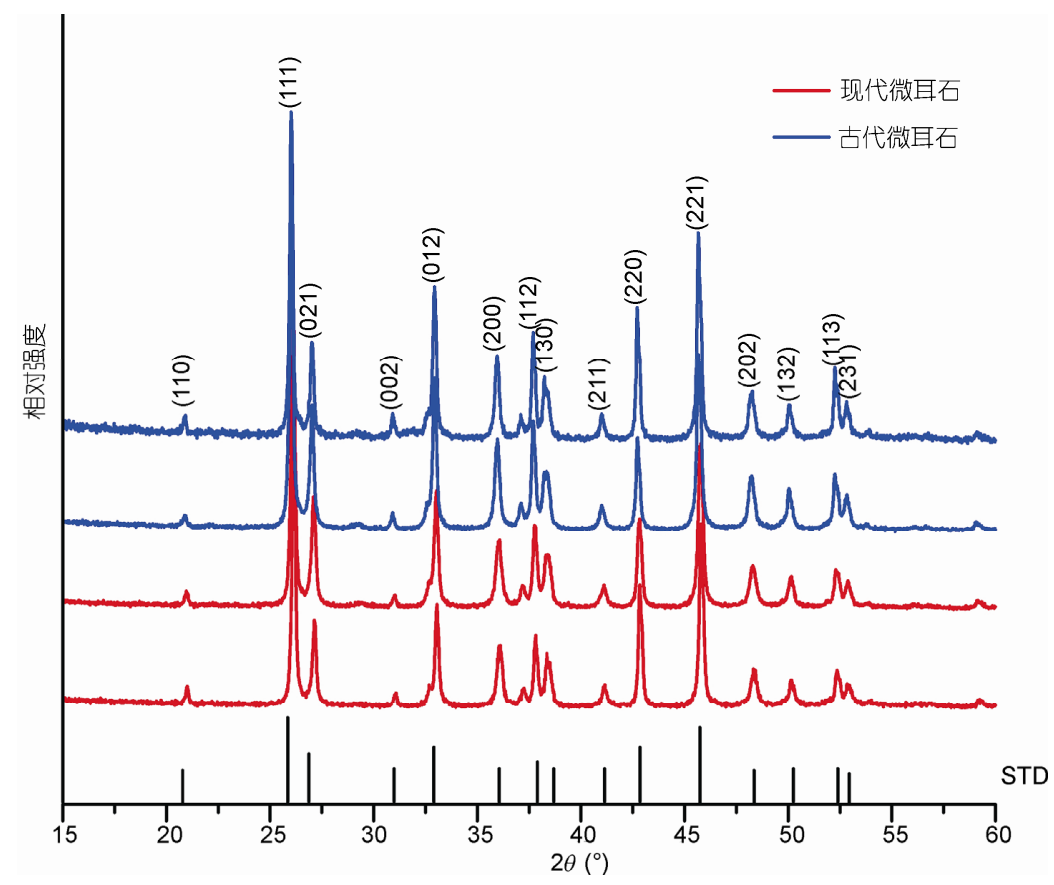

图 3 青海湖裸鲤现代和古代微耳石的 $\mathrm{X}$-衍射图谱

STD 是文石的标准图谱, 图谱中特征峰上方括号内的数值是矿物的晶面指数. 现代微耳石数据来自周玲等(2012)

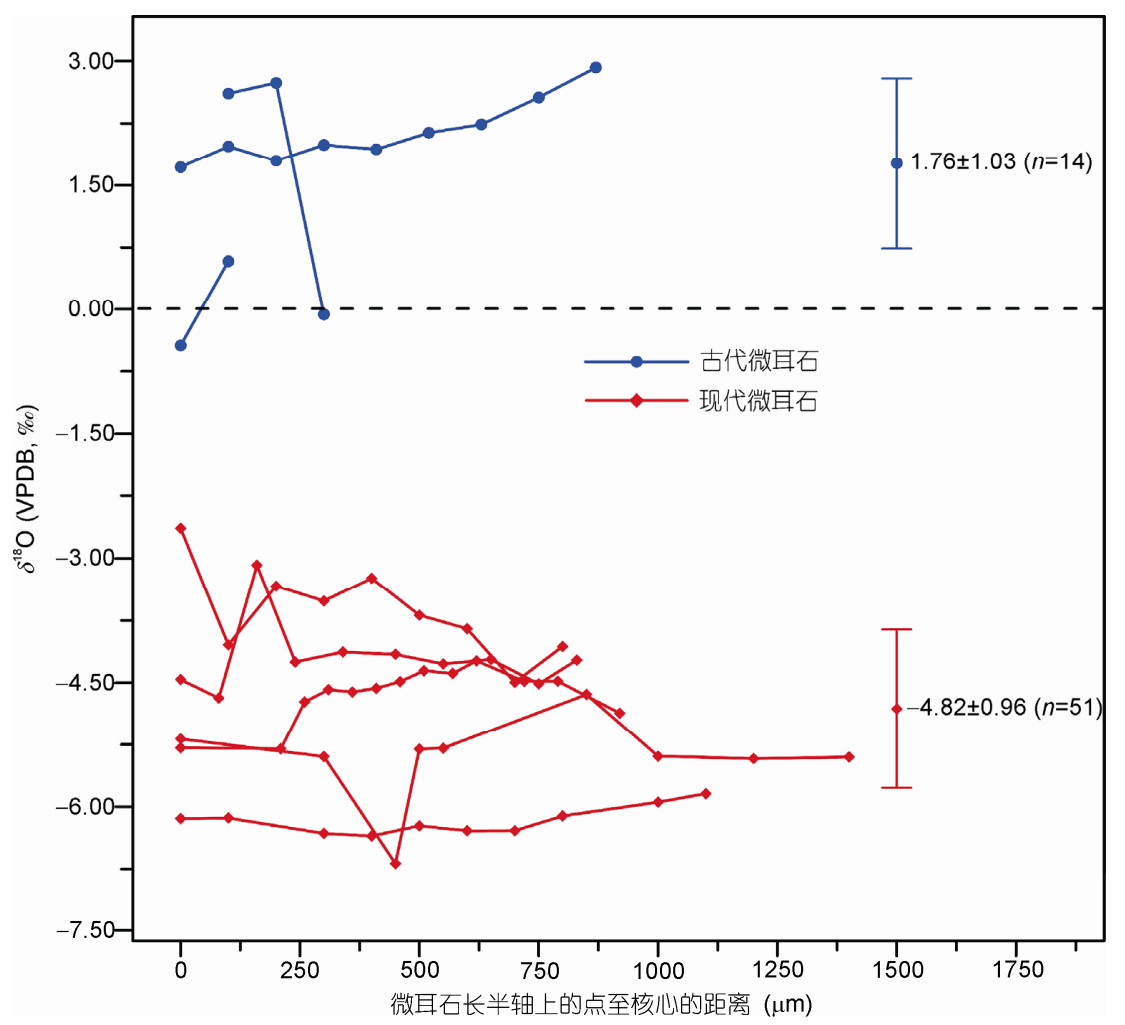

图 4 青海湖裸鲤现代和古代微耳石长半轴上 $\delta^{18} \mathrm{O}$ 值的比较

右边标注的数字为两者的平均值和标准偏差(s.d.), 显示出两者之间系统的差异 


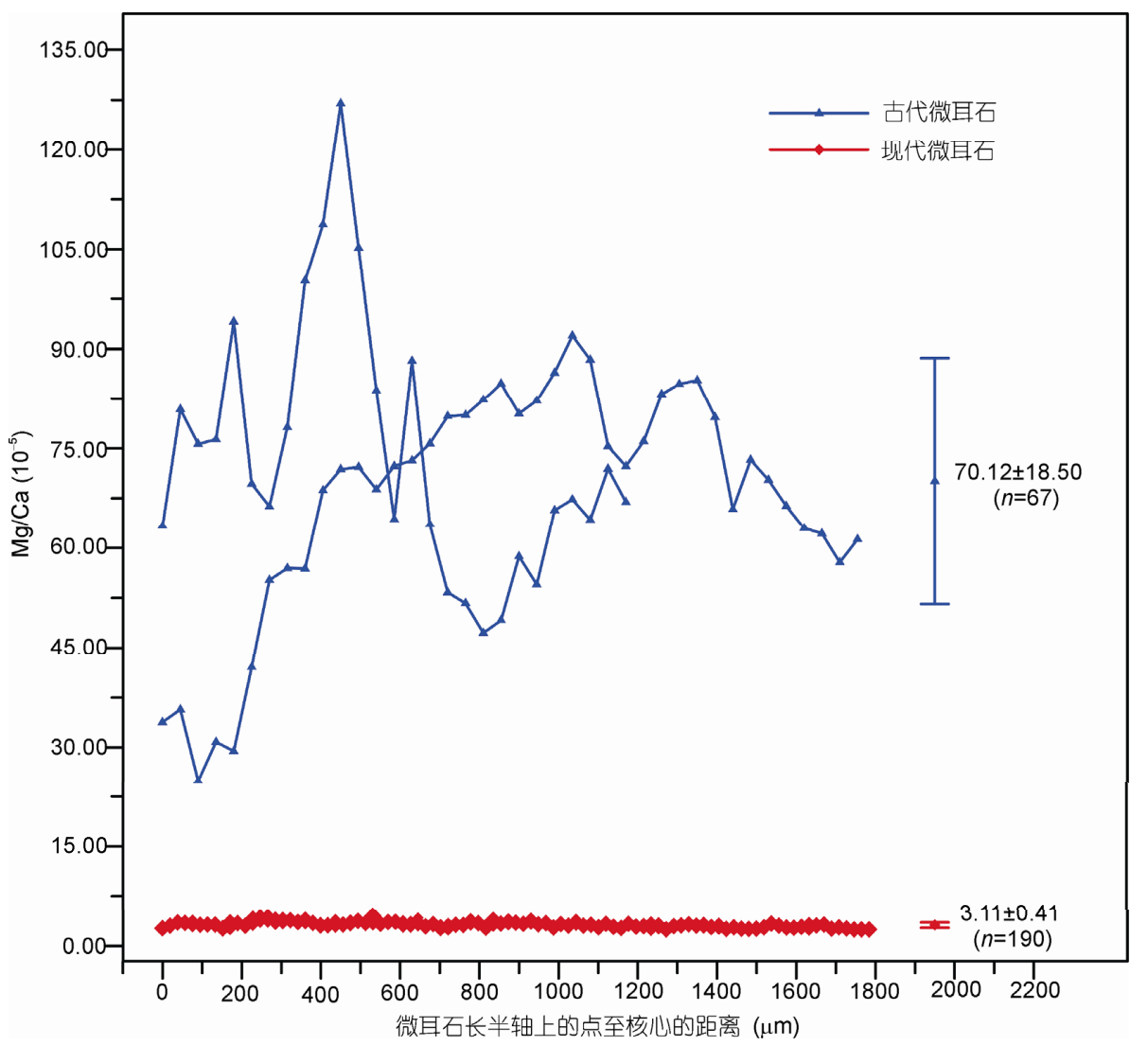

图 5 青海湖裸鲤现代和古代微耳石长半轴上 $\mathrm{Mg} / \mathrm{Ca}$ 比值的比较

右边标注的数字为两者的平均值和标准偏差(s.d.), 显示出两者之间系统的差异

常用来开展古气候、古生态和古地理等方面的研究 (Nolf, 1995; Patterson 等, 1993; Breard 和 Stringer, 1999). 因 $0.15 \mathrm{Ma}$ 前青海湖与黄河隔离, 青海湖裸鲤 与现在黄河中的花斑裸鲤发生了地理隔离(何德奎等, 2003), 青海湖裸鲤成为青海湖特有的鱼类. 因此, 沉 积物中赋存的裸鲤耳石为研究不同时期青海湖的环 境状况和湖泊演化提供了可能. 然而, 由于耳石个体 微小, 不易在沉积物中获得, 因此相关的研究在国内 还未见报道. 本文通过对埋藏于青海湖西侧湖岸 300 680 年前湖滨相沉积物中青海湖裸鲤古代微耳 石的矿物分析, 确定其矿物类型没有发生改变, 依然 是纯文石，进而利用古代微耳石的微量元素和氧同 位素组成, 及其与现代耳石微化学组成的比较, 可以 探讨其生活水体的水化学和气候状况.

鱼耳石中的化学元素主要来自鱼类生活的水体, 因此耳石的微化学组成记录了鱼体当时生活水体的 化学信息(Elsdon 和 Gillanders, 2003; 周玲等, 2012).
我们的分析结果表明, 古代青海湖裸鲤古代微耳石 的 $\delta^{18} \mathrm{O}$ 和 $\mathrm{Mg} / \mathrm{Ca}$ 值均明显高于现代青海湖裸鲤微耳 石. 鱼类耳石的 $\delta^{18} \mathrm{O}$ 值取决于耳石形成时鱼体生活 水体的温度和水体 $\delta^{18} \mathrm{O}$ 值(Patterson 等, 1993; Høie 等, $2004)$, 前者与耳石 $\delta^{18} \mathrm{O}$ 值成反相关, 后者主要取决 于降水量和蒸发量 $(\mathrm{P} / \mathrm{E})$ 比、降水 $\delta^{18} \mathrm{O}$ 和径流量. 因 此, 古代微耳石比现代微耳石高得多的 $\delta^{18} \mathrm{O}$ 值表明, 当时青海湖裸鲤生活的水体具有比现代青海湖低得 多的温度, 或具有极高 $\delta^{18} \mathrm{O}$ 值的降水, 或强烈的蒸 发. 然而, 对于青海湖而言, 前两者是不可能的. 以 文石而言, 温度每降低 $1{ }^{\circ} \mathrm{C}$, 其 $\delta^{18} \mathrm{O}$ 值升高 $0.26 \%$ 。 (Kim 等, 2007). 那么, 如果只考虑温度效应, 古代微 耳石比现代微耳石平均高了约 $6 \%$ 的 $\delta^{18} \mathrm{O}$ 值, 当时的 平均水温需至少比现在低 $23^{\circ} \mathrm{C}$. 很显然, 即使明朝 时期的气候属于小冰期，也不可能出现如此低的水 温. 另一方面，在水位下降或盐度增高的情形下，青 海湖内形成的介形类壳体和自生碳酸盐的 $\delta^{18} \mathrm{O}$ 值均 
偏正(Henderson 等, 2003; Liu 等, 2009), 此与全新世 盛期青海湖高湖面时介形类壳体偏负的 $\delta^{18} \mathrm{O}$ 值 (Lister 等, 1991; An 等, 2012)相对应. 因此, 青海湖裸 鲤古代微耳石高的 $\delta^{18} \mathrm{O}$ 值所反映的水体状况只能是 由强烈的蒸发浓缩及自生碳酸盐沉淀造成的. 更重 要的是，该水体并没有与大湖连在一起，因为生活在 比当时更低水位的、现在的裸鲤微耳石 $\delta^{18} \mathrm{O}$ 值也只 达到(-4.82 \pm 0.96$) \%$ (图 4), 所以该水体所具有的、比现 在大湖高得多的 $\delta^{18} \mathrm{O}$ 值可能反映了当时低的 $\mathrm{P} / \mathrm{E}$ 比.

与此同时，微量元素(如 $\mathrm{Mg}, \mathrm{Sr}$ 和 B 等)可以与碳 酸钙共同沉淀或以类质同象(替代铂离子)的方式进 入生物碳酸盐(如鱼耳石、介形类壳体等), 其富集程 度也主要取决于水体中相应离子的浓度, 两者往往 呈正相关关系(Campana，1999; 胡广等, 2008). 生物 对一些微量元素的吸收可能存在某种程度的“生命效 应(vital effect)”，例如介形类幼年时蜕的壳体具有高 $M g$ 和异常低的 $\operatorname{Sr}$ (Griffiths 和 Holmes, 2000). 我们最 近的研究也表明, 青海湖裸鲤微耳石上年轮的成长 (明)带具有比间歇(暗)带更高的 $\mathrm{Sr} / \mathrm{Ca}$ 比值, 它是春 夏洄游时期鱼体生活在 $\mathrm{Sr} / \mathrm{Ca}$ 比值较高的河水中的直 接反映(周玲等, 2012). 尽管如此, 本文分析的青海 湖裸鲤现代和古代微耳石的 $\mathrm{Mg} / \mathrm{Ca}$ 比值都是从耳石 核心开始的，加之微耳石与水体之间相同的分配系 数, 两者具有生长阶段的可比性; 虽然成长带和间歇 带的 $\mathrm{Mg} / \mathrm{Ca}$ 比值也存在一定的差异(图 5), 不同个体 的耳石生长速率也不尽相同, 但两者显著的系统差 异显然不是“生命效应”的结果. 因此, 青海湖裸鲤古 代微耳石高的 $\mathrm{Mg} / \mathrm{Ca}$ 值说明其生活的水体具有比现 代青海湖高得多的 $\mathrm{Mg} / \mathrm{Ca}$ 比值.

青海湖裸鲤鱼骨等残骸的采样点位于鸟岛附近, 根据上述微耳石所具有的高 $\delta^{18} \mathrm{O}$ 和 $\mathrm{Mg} / \mathrm{Ca}$ 比值推断, 当时的沉积环境可能存在两种可能性：(1) 湖水退却 形成的残余湖, 类似于现存于青海湖周边的尔海、耳 海等; (2) 布哈河改道的产物. 根据实地考察观测, 该地点周围地势平坦, 附近的布哈河并无河流改道 的痕迹. 另外, 从沉积相特征分析来看, 产出的砾石 为黑色扁平状, 水平方向整齐排布, 砾石颜色、形状 单一, 加之大量鱼骨的叠层堆积, 不可能是大范围碎 屑物质带来, 因此可以排除第二种可能. 这可以从我 们在采样点附近平坦处开挖 $50 \mathrm{~cm}$ 深所见的湖相沉 积得到进一步证实. 综合上述耳石微化学特征, 我们 判断这些鱼骨等残骸是在湖水退却形成的残余湖内
生活的青海湖裸鲤死亡后原地埋藏留下的. 结合沉 积相和鱼骨、耳石所获得的年代，我们可以进一步推 断, 青海湖湖面在小冰期前, 或者湿润小冰期时 (Chen 等, 2010), 曾达到过鱼骨残存的位置, 而这种 残余湖是由于湖水退却时遗留下来的，水体干涸后 被粉砂质类黄土所覆盖(图 2). 对于一个相对封闭的 水体, 在与大湖隔离后, 由于缺少外来水体持续补给 和交换, 水位下降, 水体中离子浓度和 $\delta^{18} \mathrm{O}$ 均会增 高, 因此青海湖裸鲤古代微耳石中比现代高得多的 $\mathrm{Mg} / \mathrm{Ca}$ 和 $\delta^{18} \mathrm{O}$ 则记录了这些残余湖与大湖隔离、经 强烈蒸发浓缩后的水化学状况.

这种蒸发浓缩现象可以从现代青海湖周边的小 湖(如尔海和一郎剑附近小湖)湖水的盐度、 $\delta^{18} \mathrm{O}$ 和 $\mathrm{Mg} / \mathrm{Ca}$ 比值得到进一步证实. 这些小湖都是因青海 湖水位下降，从大湖分隔出来的. 由于青海湖流域现 代的蒸发量远远大于降水量(低 P/E)(Jin 等, 2010), 因 此从大湖分隔后，随着蒸发浓缩、盐度增高，这些小 湖的水体均具有高于现代青海湖湖水的 $\delta^{18} \mathrm{O}$ 值和 $\mathrm{Mg} / \mathrm{Ca}$ 值(表 2). 因此, 我们可以进一步推断, 这些明 朝时期的青海湖裸鲤可能就是生活在类似于现在的 尔海等这样的与大湖分隔开的水体内的.

综合以上分析可以确定，青海湖裸鲤鱼骨残骸 采样点的位置曾被青海湖的高湖面所覆盖, 明朝时 期的湖面至少达到采样点的海拔高度. 根据现在青 海湖的地形图、青海湖裸鲤鱼骨等残骸采样点的地理 坐标以及绝对高程, 我们利用 ArcGIS 得到了明朝时 期青海湖湖岸线的位置，如图 6 所示. 据此计算，明 朝时期的青海湖湖面面积至少达到 $4480 \mathrm{~km}^{2}$, 相对 于现在青海湖的湖面面积 $\left(4260 \mathrm{~km}^{2}\right)$, 那时的湖面面 积比现在至少大 $5 \%$ 左右.

\section{4 结论}

本文通过对青海湖鸟岛附近发现的青海湖裸鲤 鱼骨的地层层位、年代学、微耳石的矿物类型及其

表 2 青海湖及周边小湖的 $\delta^{18} \mathrm{O}$ 和 $\mathrm{Mg} / \mathrm{Ca}$ 值(平均值 \pm s.d.) $)^{\mathrm{a})}$

\begin{tabular}{cccc}
\hline 湖泊名称 & 盐度 $\left(\mathrm{g} \mathrm{L}^{-1}\right)$ & $\delta^{18} \mathrm{O}(\mathrm{VSMOW}, \% \mathrm{o})$ & $\mathrm{Mg} / \mathrm{Ca}$ \\
\hline 青海湖 & $15.14 \pm 0.42$ & $2.43 \pm 0.65$ & $71.84 \pm 1.32$ \\
尔海 & 34.26 & $2.72^{*}$ & 74.54 \\
一郎尖附近小湖 & 143.84 & - & 122.22 \\
\hline
\end{tabular}

a) *处数据来自 Liu 等(2009), 其余来自金章东未发表数据 


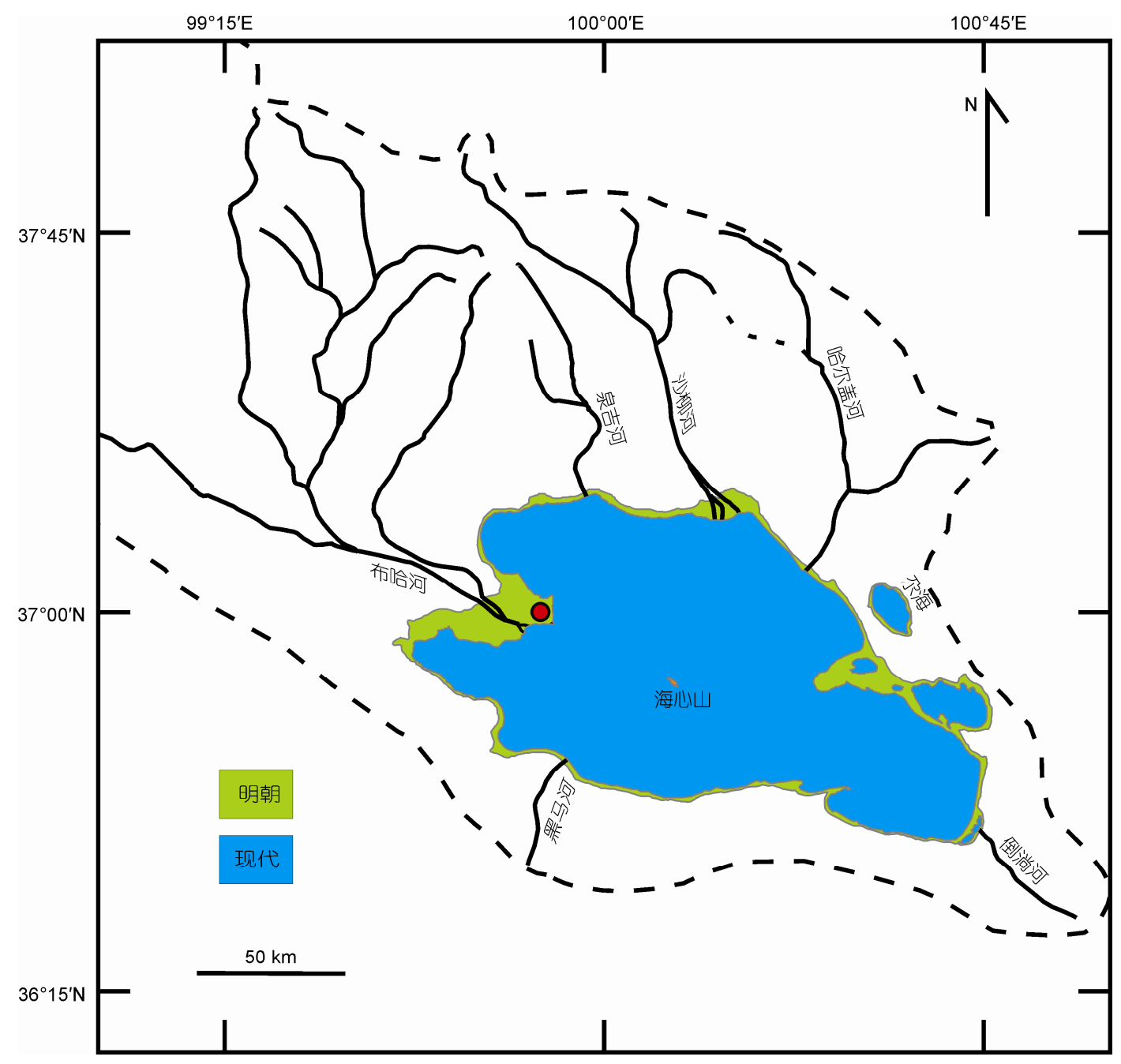

图 6 利用 ArcGIS 得到的明朝时期青海湖湖面轮廓图

根据青海湖裸鲤鱼骨产出的海拔高度绘制, 当时的湖泊面积至少比现在大 $5 \%$ 左右(绿色部分)

$\mathrm{Mg} / \mathrm{Ca}$ 和 $\delta^{18} \mathrm{O}$ 值的系统分析, 及与现代微耳石微化 学组成的比较, 认识到了青海湖在明朝时期的一次 高湖面, 及其所留下残余湖的水化学特征. 青海湖裸 鲤古代耳石和鱼骨残片的 $\mathrm{AMS}-{ }^{14} \mathrm{C}$ 定年表明, 这些 裸鲤生活的时代距今 300 680 年左右. 在明确古代微 耳石的矿物仍为纯文石的前提下, 古代微耳石微化
学分析结果表明, 高湖面所留下的残余湖具有大大 高于现代青海湖湖水的 $\mathrm{Mg} / \mathrm{Ca}$ 和 $\delta^{18} \mathrm{O}$ 值, 是水体与 大湖隔离后经历了强烈蒸发浓缩的结果. 根据裸鲤 鱼骨残骸产出的位置和海拔高度，推断明朝时期青 海湖的湖面海拔至少达到 $3202 \mathrm{~m}$, 当时的湖面面积 至少比现在大 $220 \mathrm{~km}^{2}$.

致谢西北大学柳小明老师在耳石 $\mathrm{Mg} / \mathrm{Ca}$ 比值测试中提供了帮助, 中国科学院地球环境研究所蔡演军、张海伟和曹 蕴宁对耳石 Micromill 取样及氧同位素分析、程鹏对 AMS $-{ }^{14} \mathrm{C}$ 测年进行了指导和帮助, 中国科学院地球环境 研究所肖军、万的军、汪进和李燕, 对本文的写作完成提出了很多宝贵意见, 在此一并深表谢意. 


\section{参考文献}

冯松, 汤禁苍, 周陆生. 2000. 青海湖近 600 年的水位变化. 湖泊科学, 12: 205-210

何德奎，陈毅峰，陈宜瑜，等. 2003. 特化等级裂腹鱼类的分子系统发育与青藏高原隆起. 科学通报, 48: 2354-2362

胡广, 金章东, 张飞. 2008. 利用介形类壳体 Sr、Mg 重建古环境受自生碳酸盐矿物的限制及机理探讨. 中国科学 D 辑: 地球科学, 38: 177-186

刘向军, 赖忠平. 2010. 青海湖晚第四纪湖面变化研究进展. 地球环境学报, 1: 79-89

王苏民, 李建仁. 1991. 湖泊沉积一研究历史气候的有效手段一以青海湖、岱海为例. 科学通报, 36: 54-56

王苏民, 施雅风. 1992. 晚第四纪青海湖演化研究析视与讨论. 湖泊科学, 4: 1-9

伊万娟, 李小雁, 崔步礼, 等. 2010. 青海湖流域气候变化及其对湖水位的影响. 干早气象, 28: 375-383

周玲, 金章东, 李福春, 等. 2012. 青海湖裸鲤(湟鱼)耳石的矿物组成及其 $\mathrm{Sr} / \mathrm{Ca}$ 对洄游习性的潜在示踪. 中国科学: 地球科学, 42: 1210-1217

An Z S, Colman S M, Zhou W J, et al. 2012. Interplay between the Westerlies and Asian monsoon recorded in Lake Qinghai sediments since 32 ka. Sci Reports, 2, doi: 10.1038/srep00619

Andrus C F, Crowe D E, Sandweiss D H, et al. 2002. Otolith $\delta^{18} \mathrm{O}$ record of mid-Holocene sea surface temperatures in Peru. Science, 295: $1508-1511$

Breard S Q, Stringer G L. 1999. Integrated paleoecology and marine vertebrate fauna of the Stone City Formation(Middle Eocene), Brazos River section, Texas. Trans Gulf Coast Assoc Geol Soc, 49: 132-143

Campana S E. 1999. Chemistry and composition of fish otoliths pathways: Mechanisms and applications. Mar Ecol Prog Ser, 188: 263-297

Chen F H, Chen J H, Holmes J A, et al. 2010. Moisture changes over the last millennium in the Arid Central Asia: A review, synthesis and comparison with monsoon region. Quat Sci Rev, 29: 1055-1068

Elsdon T S, Gillanders B M. 2004. Fish otolith chemistry influenced by exposure to multiple environmental variables. J Exp Mar Biol Ecol, 313 : 269-284

Elsdon T S, Gillanders B M. 2003. Reconstructing migratory patterns of fish based on environmental influences on otolith chemistry. Rev Fish Biol Fisher, 13: 219-235

Gago-Duport L, Briones M J I, Rodríguez J B, et al. 2008. Amorphous calcium carbonate biomineralization in the earthworm's calciferous gland: Pathways to the formation of crystalline phases. J Struct Biol, 162: 422-435

Gillanders B M, Munro A R. 2012. Hypersaline waters pose new challenges for reconstructing environmental histories of fish based on otolith chemistry. Limnol Oceanogr, 57: 1136-1148

Griffiths H I, Holmes J A. 2000. Non-marine Ostracods and Quaternary Palaeoenvironments. London: Quaternary Research Association. 1-187

Henderson A C G, Holmes J A, Zhang J, et al. 2003. A carbon- and oxygen-isotope record of recent environmental change from Qinghai Lake, NE Tibetan Plateau. Chin Sci Bull, 48: 1463-1468

Høie H, Otterlei E, Folkvord A. 2004. Temperature-dependent fractionation of stable oxygen isotopes in otoliths of juvenile cod (Gadus morhua L.). ICES J Mar Sci, 61: 243-251

Jamieson J C. 1953. Phase equilibrium in the system calcite-aragonite. J Chem Phys, 21: 1385-1390

Jin Z D, You C F, Wang Y, et al. 2010. Hydrological and solute budgets of Lake Qinghai, the largest lake on the Tibetan Plateau. Quat Int, 218: $151-156$

Kerr L A, Andrews A H, Frantz B R, et al. 2004. Radiocarbon in otoliths of yelloweye rockfish (Sebastes ruberrimus): A reference time series for the coastal waters of southeast Alaska. Can J Fish Aquat Sci, 61: 443-451

Kim S-T, O'Neil J R, Hillaire-Marcel C, et al. 2007. Oxygen isotope fractionation between synthetic aragonite and water: Influence of temperature and $\mathrm{Mg}^{2+}$ concentration. Geochim Cosmochim Acta, 71: 4704-4715

Li X Y, Xu H Y, Sun Y L, et al. 2007. Lake-level change and water balance analysis at Lake Qinghai, west China during recent decades. Water Resour Manage, 21: 1505-1516

Lister G S, Kelts K R, Chen K Z, et al. 1991. Lake Qinghai, China: Closed-basin lake levels and the oxygen isotope record for ostracoda since the latest Pleistocene. Paleogeogr Paleoclimatol Paleoecol, 84: 141-162

Liu W G, Li X Z, Zhang L, et al. 2009. Evaluation of oxygen isotopes in carbonate as an indicator of lake evolution in arid areas: The modern Qinghai Lake, Qinghai-Tibet Plateau. Chem Geol, 268: 126-136

Madsen D B, Ma H Z, Rhode D, et al. 2008. Age constraints on the late Quaternary evolution of Qinghai Lake, Tibetan Plateau. Quat Res, 69: 316-325 
Nolf D. 1985. Otolithi piscium. In: Schultze H P, ed. Handbook of Paleoichthyology. New York: Gustav Fischer Verlag. 1-145

Patterson W P, Smith G R, Lohmann K C. 1993. Continental paleothermometry and seasonality using the isotopic composition of aragonitic otoliths of freshwater fishes. In: Swart P K, et al. eds. Climate Change in Continental Isotopic Records. Washington D C: Geophysical Monograph Series. 191-202

Reimer P J, Baillie M G L, Bard E, et al. 2009. IntCa109 and Marine09 radiocarbon age calibration curves, 0-50000 years cal BP. Radiocarbon, 51: $1111-1150$

Rhode D, Ma H Z, Madsen D B, et al. 2010. Paleoenvironmental and archaeological investigation at Qinghai Lake, western China: Geomorphic and chronometric evidence of lake level history. Quat Int, 218: 29-44

Watanabe T, Nakamura T, Nara F W, et al. 2009. High-time resolution AMS ${ }^{14} \mathrm{C}$ data sets for Lake Baikal and Lake Hovsgol sediment cores: Changes in radiocarbon age and sedimentation rates during the transition from the last glacial to the Holocene. Quat Int, 205: 12-20

Yan J P, Hinderer M, Einsele G. 2002. Geochemical evolution of closed-basin lakes, general model and application to Lakes Qinghai and Turkana. Sediment Geol, 148: 105-122

Yuan S X, Wu X H, Gao S J, et al. 2000. Comparison of different bone pretreatment methods for AMS ${ }^{14} \mathrm{C}$ dating. Nucl Instrum Methods Phys Res Sect B-Beam Interact Mater Atoms, 172: 424-427

Zhang H C, Peng J L, Ma Y Z, et al. 2004. Late Quaternary palaeolake levels in Tengger Desert, NW China. Paleogeogr Paleoclimatol Paleoecol, 211: $45-58$ 